\title{
Aspectos epidemiológicos, clinicopatológicos e imuno-histoquímicos de carcinomas de células escamosas vulvares em 33 vacas $^{1}$
}

\author{
Fábio B. Rosa ${ }^{2}$, Glaucia D. Kommers ${ }^{3 *}$, Ricardo B. Lucena², Glauco J.N. Galiza ${ }^{2}$, \\ Camila Tochetto $^{2}$, Taiara M. Silva ${ }^{4}$ e Isadora P. Silveira ${ }^{4}$
}

\begin{abstract}
Rosa F.B., Kommers G.D., Lucena R.B., Galiza G.J.N., Tochetto C., Silva T.M. \& Silveira I.P. 2012. [Epidemiological, clinicopathological and immunohistochemical aspects of vulval squamous cell carcinomas in 33 cows.] Aspectos epidemiológicos, clinicopatológicos e imuno-histoquímicos de carcinomas de células escamosas vulvares em 33 vacas. Pesquisa Veterinária Brasileira 32(11):1127-1132. Laboratório de Patologia Veterinária, Departamento de Patologia, Universidade Federal de Santa Maria, Camobi, Santa Maria, RS 97105-900, Brazil. E-mail: glaukommers@yahoo.com

Vulvar squamous cell carcinomas (VSCCs) in cattle were retrospectively studied regarding the prevalence, epidemiology, clinicopathological, and immunohistochemical aspects. The degree of vulvar pigmentation was also evaluated. In the 48 years analyzed, necropsy and biopsy reports of 7,483 cattle were found. Out of these, $664(8.87 \%)$ cases of various neoplasms were identified; 33 (4.97\%) of these cases were of VSCCs. Nineteen cows were Holstein, three were Charolais, one was Jersey, and 10 were mix breed cows. Grossly, the main change was vulvar swelling, with bleeding and concomitant myiasis. The tumor masses were firm, ulcerated and with yellow areas. It was possible to reevaluate microscopically 30 out of the 33 cases. Eight of them were well differentiated, 17 were moderately differentiated, and five were poorly differentiated VSCCs. The evaluation of squamous intraepithelial lesions (SILs) was performed in 21 cases. Epithelial hyperplasia was observed in 10 cases, mild dysplasia in two, moderate in one, and severe in five cases; in three cases no SILs were observed. Fontana-Masson stain for melanin was performed in 21 cases. In 17 cases the epidermal pigmentation was absent; it was mild in two and moderate in other two cases. Independently of the degree of differentiation, most neoplastic keratinocytes were strongly positive for bovine pancytokeratine through the immunohistochemistry (IHC) technique. Bovine papillomavirus was not detected by IHC in this study.

INDEX TERMS: Vulvar neoplasms, squamous cell carcinoma, cattle diseases, immunohistochemistry.
\end{abstract}

RESUMO.- Carcinomas de células escamosas vulvares (CCEVs) em bovinos foram estudados retrospectivamente quanto à prevalência, epidemiologia, quadro clinicopatológico e aspectos imuno-histoquímicos. 0 grau de pigmentação da pele vulvar foi também avaliado. Nos 48 anos

\footnotetext{
${ }^{1}$ Recebido em 23 de julho de 2012.

Aceito para publicação em 9 de agosto de 2012.

${ }^{2}$ Programa de Pós-Graduação em Medicina Veterinária, área de concentração em Patologia Veterinária, Centro de Ciências Rurais (CCR), Universidade Federal de Santa Maria (UFSM), Camobi, Santa Maria, RS 97105900, Brasil.

${ }^{3}$ Laboratório de Patologia Veterinária, Departamento de Patologia, Centro de Ciências da Saúde, UFSM, Av. Roraima 1000, Santa Maria, RS 97105900. *Autor para correspondência: glaukommers@yahoo.com

${ }^{4}$ Curso de Medicina Veterinária, CCR-UFSM, Santa Maria, RS. Bolsista PIBIC/CNPq.
}

analisados retrospectivamente, foram computados materiais de necropsias e biópsias de 7.483 bovinos recebidos no Laboratório de Patologia Veterinária da UFSM. Desses, em $664(8,87 \%)$ casos de neoplasmas foram identificados, sendo $33(4,97 \%)$ casos de CCEVs. Dezenove eram vacas da raça Holandesa, três da Charolesa, uma era Jersey e 10 eram sem raça definida. A principal alteração macroscópica foi aumento de volume vulvar, sangrante e com miíase concomitante. As massas tumorais eram firmes, ulceradas e com áreas amarelas. Foi possível reavaliar microscopicamente 30 dos 33 casos. Desses, oito eram CCEVs bem diferenciados, 17 eram moderadamente diferenciados e cinco eram pobremente diferenciados. A avaliação de lesões intraepiteliais escamosas (LIEs) foi realizada em tecidos de 21 casos que tinham epitélio de revestimento. Hiperplasia epitelial foi observada em 10 casos; displasia leve em dois, 
moderada em um e acentuada em cinco casos; em três casos não havia LIEs. A técnica de Fontana-Masson para melanina foi realizada em 21 casos. Desses, em 17 a pigmentação do epitélio da epiderme vulvar era ausente, em dois era leve e em outros dois era moderada. Independentemente do grau de diferenciação dos CCEVs, houve imunomarcação acentuada da maioria dos ceratinócitos neoplásicos para pancitoceratina bovina pela técnica de imuno-histoquímica (IHQ). Papilomavírus bovino não foi detectado pela IHQ neste estudo.

TERMOS DE INDEXAÇÃO: Neoplasmas vulvares, carcinoma de células escamosas, doença de bovinos, imuno-histoquímica.

\section{INTRODUÇÃO}

O carcinoma de células escamosas (CCE) cutâneo é um tumor maligno das células epidérmicas com diferenciação para ceratinócitos. Este neoplasma na pele é relativamente comum, de crescimento lento, invasivo e ocasionalmente metastático (Goldschmidt \& Hendrick 2002, Ginn et al. 2007). O CCE vulvar (CCEV) é bem reconhecido em vacas, cabras e ovelhas que vivem em áreas onde há muita exposição à luz solar. Os CCEVs podem ser ulcerativos ou proliferativos, são ocasionalmente invasivos e raramente metastáticos (MacLachlan \& Kennedy 2002).

0 CCEV é responsável por perdas econômicas devido à redução na vida reprodutiva (Meyers \& Read 1990) ou às condenações em abatedouros (Yeruham et al. 1999). Apesar de alguns estudos recentes relatarem, dentre outros neoplasmas em bovinos, a prevalência de CCEVs em algumas regiões do país (Ramos et al. 2007, Keller et al. 2008, Lucena et al. 2011), há escassez de detalhamento dos aspectos epidemiológicos e clínico-patológicos desses neoplasmas em vacas no Brasil, justificando assim a realização deste estudo.

Os objetivos deste trabalho foram relatar a ocorrência de diagnósticos de CCEVs em bovinos na área de abrangência do Laboratório de Patologia Veterinária da Universidade Federal de Santa Maria (LPV-UFSM), determinando a prevalência, a epidemiologia e o quadro clinicopatológico desta condição.

\section{MATERIAL E MÉTODOS}

Casos de CCEVs foram pesquisados dentre os protocolos de necropsias e de exames histopatológicos de bovinos provenientes dos arquivos do LPV-UFSM, num período de 48 anos (1964-2011). Dos protocolos foram agrupadas informações quanto à idade, à raça, ao histórico clínico e à patologia.

Quando disponíveis, amostras de CCEVs foram recuperadas do arquivo de blocos e seções histológicas de $3 \mu \mathrm{m}$ foram coradas com hematoxilina e eosina (HE) e examinadas sob microscopia de luz. Cada CCEV foi graduado como bem, moderadamente ou pobremente diferenciado, de acordo com os critérios de Goldschmidt \& Hendrick (2002). A presença e a intensidade da reação desmoplásica intratumoral foi graduada em leve, moderada ou acentuada. Quando o epitélio de revestimento estava presente nas seções analisadas, foi ainda computada a ocorrência de lesões intraepiteliais escamosas (LIEs), classificadas como hiperplasia ou displasia epitelial. A displasia foi graduada em leve, moderada ou acentuada, de acordo com os critérios de Gale et al. (2005). A técnica de Fontana-Masson (FM) modificada (contracoloração com verde brilhante) para demonstração de melanina foi realizada em todos os casos em que a epiderme estava presente, para determinar seu grau de pigmentação (GP). 0 GP foi classificado em ausente, leve (restrito à camada basal), moderado (na camada basal e estendendo-se menos intensamente pelas demais camadas) ou acentuado (intenso em todas as camadas epidérmicas). Seções histológicas de peles da região perineal pigmentadas, pouco pigmentadas e não pigmentadas de bovinos sem alterações cutâneas foram utilizadas como controles para o FM.

Para a avaliação dos padrões morfológicos de migração e invasão dos CCEVs foi realizada a técnica de imuno-histoquímica (IHQ) utilizando o anticorpo (Ac) policlonal anti-pancitoceratina bovina (código Z-0622) produzido em coelho ${ }^{5}$ (1:2.000). Em 14 casos com alterações no epitélio de revestimento (hiperplasia ou displasia marcadas), foi realizada IHQ utilizando o Ac policlonal anti-papilomavírus bovino (BPV-1; código B-0580) produzido em coelho $^{5}$ (1:500). Foram utilizadas lâminas silanizadas com seções histológicas de $3 \mu \mathrm{m}$. Após a desparafinização e reidratação dos tecidos, foi feita a recuperação antigênica com TRIS-EDTA em pH 9,0 (para o Ac anti-pancitoceratina) e tampão citrato em $\mathrm{pH}$ 6,0 (para o Ac anti-papilomavírus), seguido por bloqueio da peroxidase endógena com peróxido de hidrogênio a 3\%. 0 bloqueio das reações inespecíficas foi realizado com solução de caseína. A incubação com os Acs primários foi por $60 \mathrm{~min}$ a $37^{\circ} \mathrm{C}$. $\mathrm{O} \mathrm{Ac}$ secundário biotinilado e o complexo estreptavidina-peroxidase ${ }^{5}$ (LSAB+System-HRP) foram utilizados consecutivamente, incubados à temperatura ambiente por $30 \mathrm{~min}$, e marcados com tetracloreto de 3-3'diaminobenzidina ${ }^{5}$ (DAB). As seções foram contracoradas com hematoxilina de Harris, desidratadas e montadas com resina sintética e lamínulas. Utilizaram-se controles positivos para cada Ac. Como controle negativo, foram utilizadas as mesmas seções a serem testadas, com a substituição do anticorpo primário por diluente de anticorpo.

\section{RESULTADOS}

Nos 48 anos analisados, foram examinados materiais de necropsias ou biópsias de 7.483 bovinos (excluindo casos experimentais). Desses, foram identificados $664(8,87 \%)$ casos de neoplasmas, sendo 33 (4,97\%; $0,44 \%$ sobre o total de bovinos examinados) casos de CCEVs. A idade das vacas afetadas variou de 2-10 anos (sendo 70\% delas entre 4 e 7 anos). A raça foi informada nas 33 vacas; dessas, 19 eram da raça Holandesa $(57,57 \%)$, três da Charolesa $(9,09 \%)$, uma era Jersey $(3,03)$ e 10 eram sem raça definida $(30,30 \%)$.

O tempo de evolução, a macroscopia dos tumores e o grau de pigmentação da vulva não foram consistentemente informados nos históricos clínicos. Entretanto, algumas observações importantes foram computadas. Quando a evolução dos tumores foi informada (12/33), esta variou de vinte dias a nove meses. Em três casos as lesões foram observadas cerca de dois meses após o parto. Em uma vaca, outro CCEV foi observado no lábio vulvar contralateral três anos após a retirada do primeiro, e havia CCE na terceira pálpebra (bilateralmente). Macroscopicamente, as principais alterações informadas foram: presença de feridas sangrantes $(9 / 33)$, com míase concomitante $(9 / 33)$ e aumento de volume vulvar (8/33). As massas tumorais eram firmes (7/33), ulceradas (5/33), com áreas multifocais amarelas (5/33) e aspecto granulomatoso ou de tecido de granulação (5/33). Informações esporádicas incluíam: tumor de

\footnotetext{
${ }^{5}$ DakoCytomation, Carpinteria, Califórnia, EUA.
} 
aspecto verrucoso (semelhante à couve-flor ou como nódulos brancos e friáveis) ou pedunculado, presença de papilomas vulvares e perineais (não submetidos) concomitantes e emagrecimento progressivo. Quando informado (9/33), o tamanho das massas tumorais variou de $6-20 \mathrm{~cm}$ de diâmetro. Nos casos em que os CCEVs eram grandes, houve extensão para as regiões perineal e anal. Em um caso houve formação de fístula retovaginal.

Foi possível reavaliar microscopicamente 30 dos 33 casos. A avaliação das lesões intraepiteliais escamosas (LIEs) foi realizada em 21 casos em que o epitélio de revestimento estava presente. Desses, hiperplasia epitelial foi observada em 10 casos $(47,62 \%)$. Displasia foi observada em oito casos $(38,1 \%)$ e classificada como leve em dois (25\%), moderada em um (12,5\%) e acentuada (Fig.1) em cinco casos $(62,5 \%)$; em três casos não havia LIEs $(14,28 \%)$. A distribuição das LIEs era geralmente multifocal.

A avaliação do grau de diferenciação (GD) celular dos CCEVs de 30 vacas revelou que oito eram bem diferenciados (BDs; 26,66\%), 17 eram moderadamente diferenciados (MDs; 56,66\%) e cinco eram pobremente diferenciados
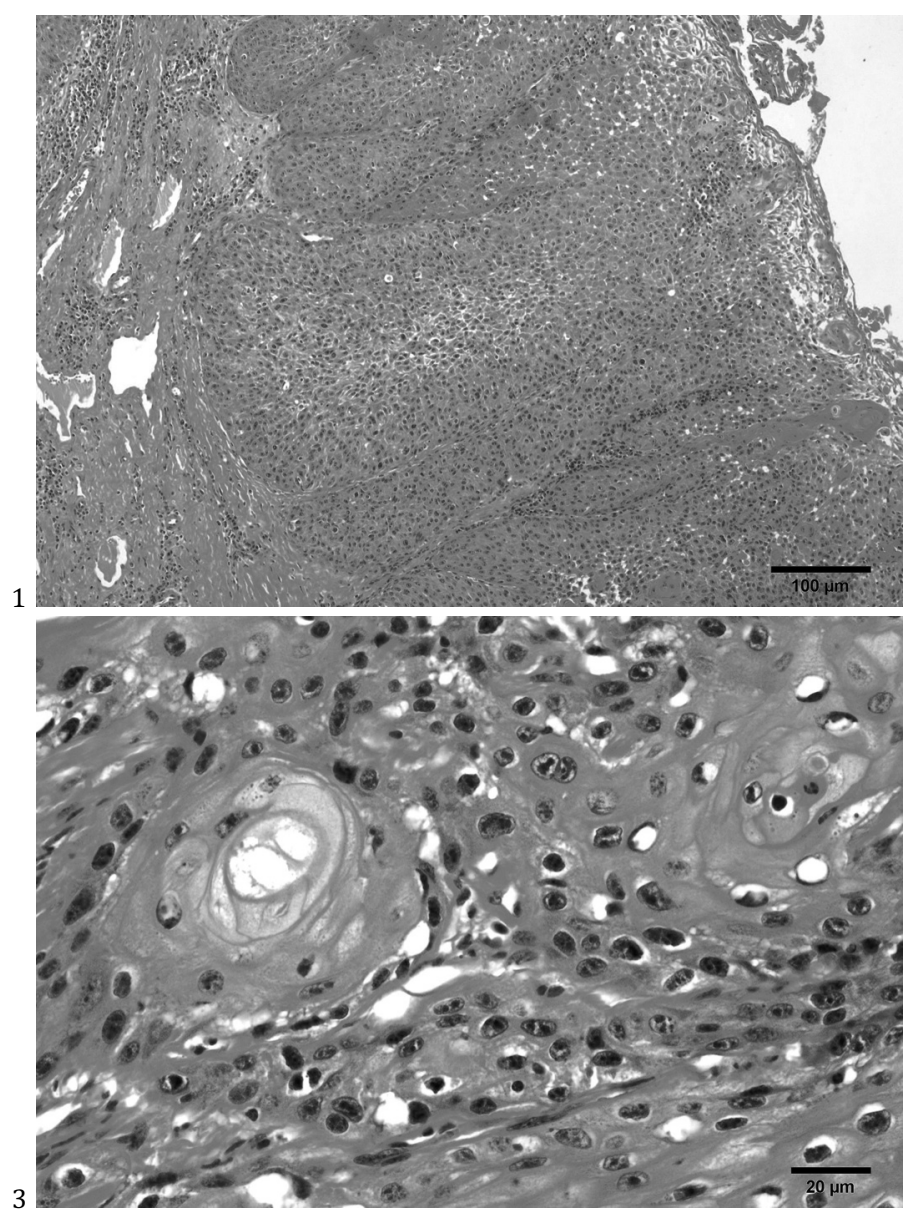

Fig.1. Displasia epidérmica acentuada na pele da vulva de vaca com carcinoma de células escamosas vulvar. Há acentuada perda da arquitetura normal celular de todas as camadas da epiderme. HE, obj.10x.

Fig.3. Carcinoma de células escamosas vulvar moderadamente diferenciado. As células neoplásicas estão arranjadas irregularmente e observa-se ceratinização ocasional. HE, obj.40x.
(PDs; 16,66\%). Nos CCEVs-BDs (Fig.2), as células neoplásicas estavam arranjadas em pequenas ou grandes ilhas ceratinizadas, com frequente formação de extensos arranjos lamelares de ceratina (pérolas de ceratina). Essas células eram cuboidais a poliédricas, com citoplasma abundante e eosinofílico, uniforme a fibrilar e com limites moderadamente distintos. 0 núcleo era redondo, com leve variação da forma e tamanho, central e com cromatina uniforme. Em alguns casos, reação granulomatosa com células gigantes multinucleadas estava presente circundando áreas com ceratina livre e às vezes mineralizada. Nos CCEVs-MDs (Fig.3), as células neoplásicas estavam arranjadas em ilhas, fitas e agregados celulares menos ceratinizados que nos BDs. Frequentemente, o interior das ilhas era composto por camadas de células necróticas ou com ceratinização individual, geralmente sem a formação de pérolas de ceratina. As células neoplásicas eram poliédricas, com citoplasma abundante, moderadamente eosinofílico, muitas vezes vacuolizado e com limites moderadamente distintos. 0 núcleo era central, grande e com cromatina frouxamente arranjada. Os CCEVs-PDs (Fig.4) eram caracterizados predominantemente por
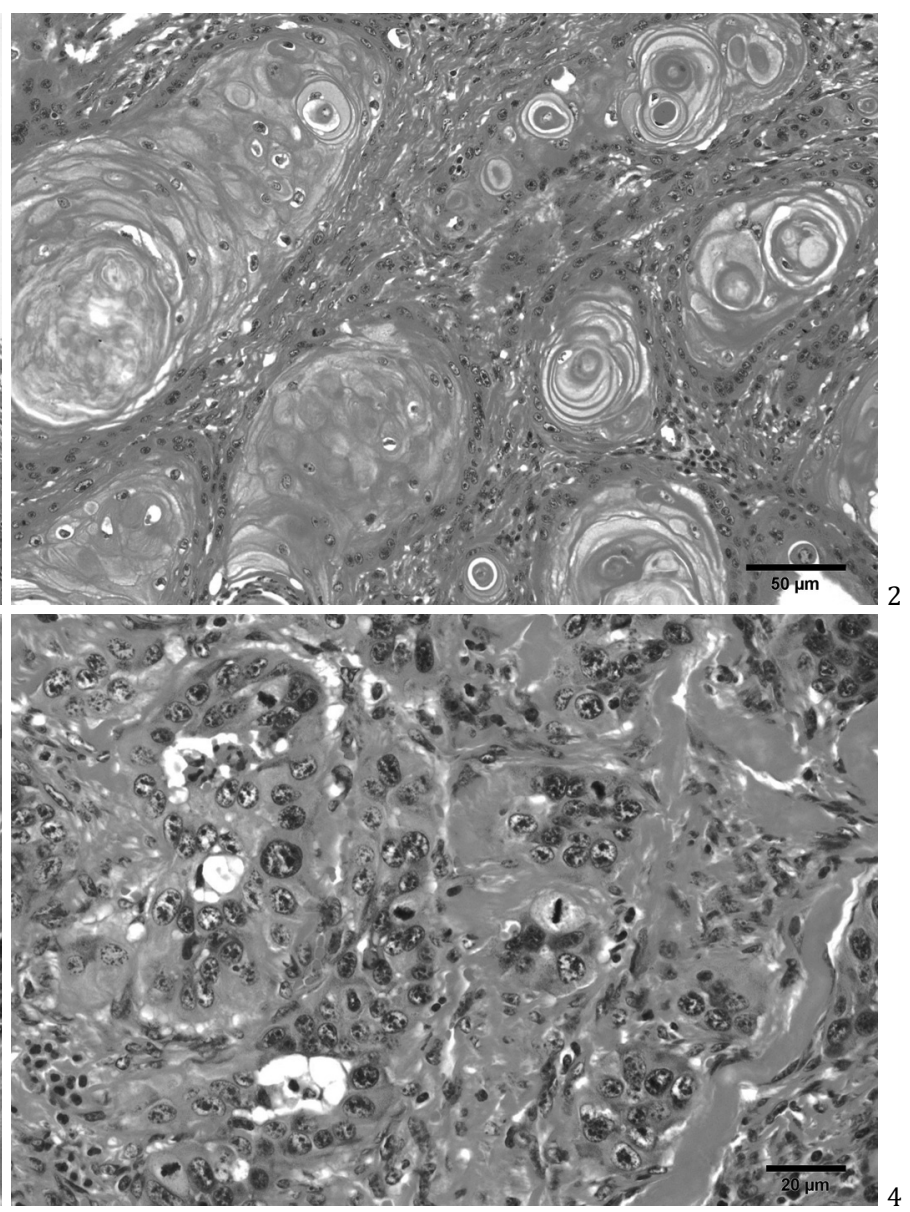

Fig.2. Carcinoma de células escamosas vulvar bem diferenciado. Há numerosas ilhas de células neoplásicas formando pérolas de ceratina centrais. HE, obj.20x.

Fig.4. Carcinoma de células escamosas vulvar pobremente diferenciado. As células neoplásicas formam pequenos agregados celulares. 0 pleomorfismo nuclear é acentuado e há várias figuras de mitose. Ceratinização não é observada. HE, obj.40x. 
pequenos agregados celulares e ceratinócitos individuais (ameboides ou fusiformes) em meio à intensa reação desmoplásica. As células neoplásicas eram pouco diferenciadas e com pleomorfismo acentuado. 0 citoplasma era poliédrico, oval ou fusiforme, abundante ou escasso, eosinofílico e com limites moderadamente distintos. 0 núcleo era redondo a oval, central ou excêntrico, com acentuada anisocariose e cromatina frouxamente ou densamente arranjada. Os padrões de migração e invasão dos ceratinócitos neoplásicos descritos acima em cada GD foram melhor caracterizados pela técnica de IHQ para citoceratina, principalmente os ceratinócitos individualizados em meio à reação desmoplásica abundante (Fig.5). Observou-se leve variação de intensidade na imunomarcação dos ceratinócitos independentemente do GD; no entanto, em todos os casos havia imunomarcação marcada da maioria dos ceratinócitos neoplásicos. A avaliação da reação desmoplásica intratumoral, presente nos 30 casos, revelou que em 13 ela era leve (43,33\%), em 14 era moderada $(46,66 \%)$ e três era acentuada $(10 \%)$.

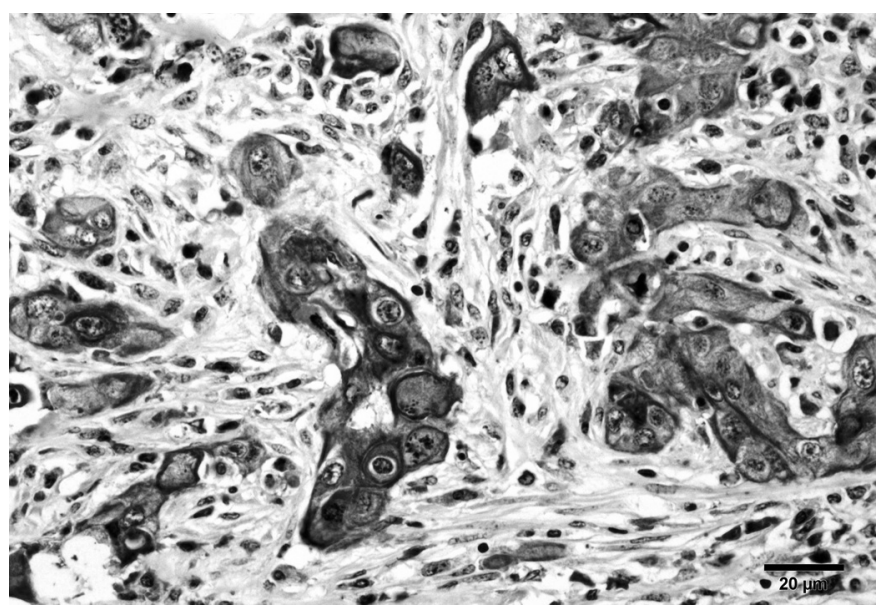

Fig.5. Carcinoma de células escamosas vulvar pobremente diferenciado. As células neoplásicas demonstram intensa imunorreatividade para citoceratina. Imuno-histoquímica (método da estreptavidina-biotina-peroxidase), obj.40x.

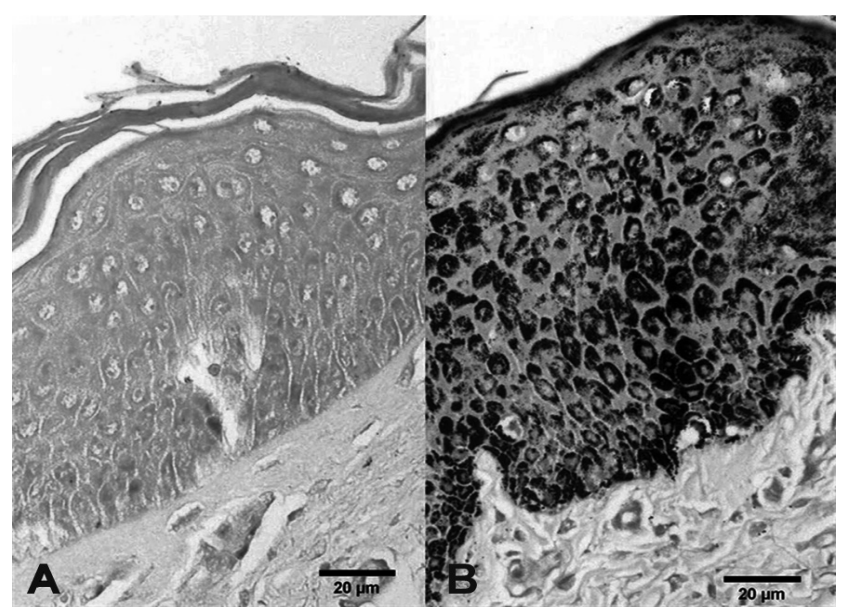

Fig.6. (A) Epiderme vulvar, que recobria um carcinoma de células escamosas, com ausência de melanina. (B) Há pigmentação difusa e acentuada da epiderme em pele vulvar pigmentada (controle). Técnica de Fontana-Masson, contracorado com verde brilhante, obj.40x.
A técnica de FM foi realizada em 21 dos 33 casos. Desses, em $17(80,95 \%)$ a pigmentação do epitélio de revestimento estava ausente (Fig.6), em dois era leve (9,52\%) e em dois era moderada $(9,52 \%)$. Os 14 casos testados pela IHQ para papilomavírus bovino foram negativos.

\section{DISCUSSÃO}

O CCEV representou aproximadamente $5 \%$ de todos os neoplasmas diagnosticados em bovinos durante os 48 anos avaliados neste estudo. A real prevalência clínica desta condição na área de influência do LPV-UFSM não é conhecida. Devido às características clínicas de fácil reconhecimento, a confirmação diagnóstica laboratorial dos CCEVs muitas vezes não ocorre (Burdin 1964). As vacas acometidas eram adultas (2-10 anos) e 70\% delas eram de raça definida, sendo dessas, $87 \%$ vacas leiteiras. As demais (30\%) eram vacas sem raça definida, não sendo possível definir o propósito do animal. Em estudos retrospectivos de casos de CCEVs, a idade das vacas variou de 3 a 10 anos (Damodaran et al. 1975, Yeruham et al. 1999). Entretanto, há descrição em novilha de 15 meses (Yeruham et al. 1999) e em vacas de até 13 anos (Wettimuny 1974).

As lesões vulvares observadas tiveram características muito semelhantes ao que é descrito na literatura para CCEVs em vacas (MacLachlan \& Kennedy 2002, Schlafer \& Miller 2007). Espessamentos esbranquiçados da pele (acantose), papilomas, cornificações cutâneas e CCEVs foram descritos em vulvas despigmentadas de vacas Ayrshire (pelagem característica com extensas áreas despigmentadas) no Quênia (Burdin 1964) e no Siri Lanka (Wettimuny 1974). Os CCEVs geralmente causam aumento de volume nas regiões vulvar (com distorção dos lábios vulvares) e perineal (Burdin 1964, Meyers \& Read 1990). São massas firmes, nodulares, branco-amareladas (Yeruham et al. 1999), ulceradas, que sangram com facilidade (Burdin 1964, Damodaran et al. 1975) e podem ter odor desagradável (Burdin 1964). Miíase concomitante é frequentemente relatada (Wettimuny 1974). Lesões vulvares muito semelhantes foram descritas em cabras no estado do Pará (Barbosa et al. 2009).

Extensões de CCEVs para a região vaginal têm sido relatadas (Damodaran et al. 1975, Meyers \& Read 1990). Em casos avançados, toda a vulva pode ser obliterada, dificultando a micção (Burdin 1964). 0 tumor pode, também, se estender para as regiões perineal e anal (Damodaran et al. 1975), com formação de fístulas (Burdin 1964), como visto em uma vaca deste estudo. Não foram reportadas metástases nas vacas deste levantamento; entretanto somente $3 / 33$ foram casos de necropsias. Os CCEVs são considerados raramente metastáticos (MacLachlan \& Kennedy 2002).

0 aspecto histológico dos CCEVs estudados seguiu os padrões característicos dos CCEs em diferentes localizações (Goldschmidt \& Hendrick 2002, MacLachlan \& Kennedy 2002). Nos 30 casos em que foi possível avaliar o grau de diferenciação (GD) celular, predominaram $(56,66 \%)$ os CCEVs moderadamente diferenciados. Em bovinos intoxicados crônica e espontaneamente por samambaia (Pteridium aquilinum) foi observado o predomínio $(67,5 \%)$ de CCEs alimentares (CCEAs) bem diferenciados (Masuda et 
al. 2011). Como o GD nesses CCEAs de bovinos foi reconhecido como o principal fator prognóstico quanto à ocorrência de metástases (Masuda et al. 2011), esses dados poderiam indicar que a maioria dos CCEVs seria potencialmente mais maligna que os CCEAs. Vale salientar, entretanto, que o potencial invasivo e metastático dos CCEs oculares (CCEOs) em bovinos não tem sido relacionado com os critérios histológicos, mas sim com o local de origem dos CCEOs (Wilcock 2007). As diferenças na etiopatogênese entre CCEAs e CCEOs em bovinos poderia ser uma possível explicação para esse fato.

Quando relacionados ao GD, os padrões de migração e invasão celulares dos CCEVs aqui estudados foram semelhantes aos observados para CCEAs em bovinos (Masuda et al. 2011). Nos CCEVs predominou $(46,66 \%)$ a reação desmoplásica intratumoral moderada, enquanto que nos CCEAs predominou $(57,5 \%)$ a reação desmoplásica acentuada (Masuda et al. 2011). Tem sido proposto que a desmoplasia possa ser utilizada pelas células malignas para aumentar sua invasividade, progressão tumoral e potencial metastático (Visser et al. 2006).

Várias alterações cutâneas têm sido consideradas como estágios iniciais no desenvolvimento de CCEVs bovinos e incluem acantose, hiperceratose, displasia, papilomas e cornificações cutâneas (Burdin 1964, Yeruham et al. 1999, Goldschmidt \& Hendrick 2002). Foi observado que essas alterações patológicas iniciais vistas em casos de CCEVs tinham alguns aspectos em comum com a ceratose actínica (dermatose solar crônica) (Burdin 1964), condição considerada como pré-maligna em humanos e em animais, e associada à exposição solar (Ginn et al. 2007). Lesões semelhantes, denominadas lesões intraepiteliais escamosas (LIEs), predizem ou antecedem a formação de CCEs de cabeça e pescoço em humanos (Gale et al. 2005). Neste estudo, LIEs foram observadas em $85,7 \%$ de 21 casos onde o epitélio de revestimento (epiderme dos lábios vulvares e o epitélio da mucosa vestibular) estava disponível nas seções analisadas, variando desde hiperplasia à displasia epitelial acentuada.

As causas definitivas para os CCEVs em vacas são desconhecidas (Meyers \& Read 1990). Entretanto, como a maioria dos casos de CCEVs tem sido descrita em áreas geográficas com maior proximidade à linha do Equador ou em regiões de altas altitudes (Burdin 1964, Meyers \& Read 1990), apesar de haver uma distribuição mundial (Meyers \& Read 1990), a exposição crônica à radiação ultravioleta (UV) pela luz solar tem sido indicada como um agente etiológico primário dos CCEVs (Burdin 1964, Wettimuny 1974, MacLachlan \& Kennedy 2002, Ginn et al. 2007).

Adicionalmente, os CCEVs têm sido relatados em áreas não pigmentadas da vulva de vacas (Burdin 1964, Wettimuny 1974, Damodaran et al. 1975, Yeruham et al. 1999). Nos casos observados em vulvas parcialmente pigmentadas, as lesões estavam confinadas à pele não pigmentada (Burdin 1964, Wettimuny 1974). A melanina é fotoprotetora e a exposição à radiação UV aumenta sua produção, frequentemente resultando em um "capuz" de grânulos de melanina sobre o núcleo (Ginn et al. 2007), protegendo assim o DNA celular. Os históricos clínicos dos casos aqui estudados não continham informações sobre a pigmentação vulvar. Com o objetivo de recuperar alguma informação sobre isso, foi realizada a técnica de FM, que detecta grânulos de melanina citoplasmáticos. Observou-se que em $80,95 \%$ dos 21 casos analisados não havia pigmentação epitelial, incluindo áreas de epitélio normal, confirmando que essa era a característica da pele vulvar daquelas vacas. Em quatro casos havia pigmentação leve ou moderada. Não foi possível saber se nesses quatro casos o tumor iniciou numa região vulvar não pigmentada e estendeu-se para uma moderada ou levemente pigmentada.

A causa dos CCEOs em bovinos é considerada multifatorial, incluindo linhagens familiares, despigmentação periocular e exposição à radiação UV (Dubielzig 2002). Uma participação do papilomavírus bovino (BPV) na gênese dos CCEOs tem sido aventada, porém não definitivamente comprovada (Dubielzig 2002, Wilcock 2007). Uma participação do BPV no desenvolvimento de CCEVs em vacas ainda é desconhecida. Entretanto, o BPV é o agente etiológico do fibropapiloma vulvar, tumor mais comum em novilhas (Schlafer \& Miller 2007). No intuito de verificar uma possível infecção por BPV concomitante com a ocorrência de CCEVs nos casos deste estudo, realizou-se a IHQ em amostras selecionadas. Todas as seções foram negativas, mesmo naquelas vacas com lesões "papilomatosas" vulvares descritas macroscopicamente.

\section{CONCLUSÕES}

Através deste estudo retrospectivo foi possível concluir que:

- os CCEVs perfizeram cerca de $5 \%$ de todos os neoplasmas que acometeram os bovinos examinados no LPV-UFSM em 48 anos;

- os CCEVs acometeram vacas adultas e principalmente de propósito leiteiro;

- grande parte das vacas tinha a vulva não pigmentada;

- clinicamente os CCEVs caracterizavam-se como aumentos de volume vulvares, sangrantes e frequentemente associados à miíases;

- houve um predomínio de CCEVs moderadamente diferenciados;

- as LIEs observadas variaram de hiperplasia à displasia epitelial acentuada;

- papilomavírus bovino não foi detectado pela técnica de IHQ neste estudo.

\section{REFERÊNCIAS}

Barbosa J.D., Duarte M.D., Oliveira C.M.C., Reis A.B., Peixoto T.C., Peixoto P.V. \& Brito M.F. 2009. Carcinoma de células escamosas perineal em cabras no Pará. Pesq. Vet. Bras. 29(5):421-427.

Burdin M.L. 1964. Squamous carcinoma of the vulva of cattle in Kenya. Res. Vet. Sci. 5:497-505.

Damodaran S., Sundararaj A. \& Ramakrishnan R. 1975. Vulvar carcinoma in bovines. Indian Vet. J. 52:602-604.

Dubielzig R.R. 2002. Tumors of the eye, p.739-754. In: Meuten D.J. (Ed.), Tumors in Domestic Animals. $4^{\text {th }}$ ed. Iowa State Press, Ames.

Gale N., Pilch B.Z., Sidransky D., Westra W.H. \& Califano J. 2005. Pathology and Genetics of Head and Neck Tumours. IARC Press, Lyon. 430p.

Ginn P.E., Mansell J.E.K.L. \& Rakich P.M. 2007. Skin and appendages, p.553- 
781. In: Maxie M.G. (Ed.), Jubb, Kennedy and Palmer's Pathology of Domestic Animals. Vol.1. $5^{\text {th }}$ ed. Elsevier, Philadelphia.

Goldschmidt M.H. \& Hendrick M.J. 2002. Tumors of the skin and soft tissues, p.45-118. In: Meuten D.J. (Ed.), Tumors in Domestic Animals. $4^{\text {th }}$ ed. Iowa State Press, Ames.

Keller D., Rönnau M., Gusmão M.A. \& Torres M.B.A.M. 2008. Casuística de carcinoma epidermóide cutâneo em bovinos do campus Palotina da UFPR. Acta Sci. Vet. 36(2):155-159.

Lucena R.B., Rissi D.R., Kommers G.D., Pierezan F., Oliveira-Filho J.C., Macêdo J.T.S.A., Flores M.M. \& Barros C.S.L. 2011. A retrospective study of 586 tumours in Brazilian cattle. J. Comp. Pathol. 145(1):20-24.

MacLachlan N.J. \& Kennedy P.C. 2002. Tumors of genital systems, p.547573. In: Meuten D.J. (Ed.), Tumors in Domestic Animals. $4^{\text {th }}$ ed. Iowa State Press, Ames.

Masuda E.K., Kommers G.D., Martins T.B., Barros C.S.L. \& Piazer J.V.M. 2011. Morphological factors as indicators of malignancy of squamous cell carcinomas in cattle exposed naturally to bracken fern (Pteridium aquilinum). J. Comp. Pathol. 144(1):48-54.
Meyers S.A. \& Read W.K. 1990. Squamous cell carcinoma of the vulva in a cow. J. Am. Vet. Med. Assoc. 196(10):1644-1646.

Ramos A.T., Norte D.M., Elias F. \& Fernandes C.G. 2007. Carcinoma de células escamosas em bovinos, ovinos e equinos: estudo de 50 casos no sul do Rio Grande do Sul. Braz. J. Vet. Res. Anim. Sci. 44:5-13.

Schlafer D.H. \& Miller R.B. 2007. Female genital system, p.429-564. In: Maxie M.G. (Ed.), Jubb, Kennedy and Palmer's Pathology of Domestic Animals. Vol.3. $5^{\text {th }}$ ed. Elsevier, Philadelphia.

Visser K.E., Eichten A. \& Coussens L.M. 2006. Paradoxical roles of the immune system during cancer development. Nat. Rev. Cancer 6:24-37.

Wettimuny S.G.S. 1974. Neoplastic and proliferative lesions of the vulva of Ayrshire cattle in Sri Lanka. Ceylon Vet. J. 22(1/2):17-20.

Wilcock B.P. 2007. Eye and ear, p.459-552. In: Maxie M.G. (Ed.), Jubb, Kennedy and Palmer's Pathology of Domestic Animals. Vol.1. $5^{\text {th }}$ ed. Elsevier, Philadelphia.

Yeruham S., Perl S., Orgad U. \& Yakobson B. 1999. Tumors of the vulva and vagina in cattle: A 10-year survey. Vet. J.158(3):237-239. 